\title{
Crítica, RazÃo e SOCIEdAde: CONVERGÊNCIA E PARAlELISMO ENTRE FouCAUlt E AdORnO \& HorkHEIMER http://dx.doi.org/10.1590/1984-0292/1049
}

Leomir Cardoso Hilário ${ }^{I} \star$, Eduardo Leal Cunha ${ }^{I I}$

${ }^{I}$ Universidade do Estado do Rio de Janeiro, Rio de Janeiro, RJ, Brasil

${ }^{I I}$ Universidade Federal de Sergipe, São Cristóvão, SE - Brasil

Resumo

Este artigo parte do ponto de vista defendido por Axel Honneth, no qual Foucault e Habermas são compreendidos como desenvolvimentos rivais do campo problemático aberto pela Escola de Frankfurt, Adorno e Horkheimer em particular. Propomos que é a conduta diante do Iluminismo que afasta Habermas e Honneth de Foucault e também de Adorno e Horkheimer. Tecemos, assim, uma costura entre Foucault e a primeira geração da Escola de Frankfurt, que se apoia inicialmente na crítica de Honneth tanto a um quanto a outro, para em seguida ultrapassá-la, mostrando, ao mesmo tempo, os pontos em comum - centrados na crítica radical da razão - e os motivos para considerá-los responsáveis por empreitadas filosóficas distintas.

Palavras-chave: Teoria Crítica; Escola de Frankfurt; Foucault; Adorno; Horkheimer.

\section{Critique, Reason and society: COnVERGence And}

\section{PARALLELISM BETWEEN FOUCAULT AND AdORNO \& HoRKHEIMER}

\section{Abstract}

This article starts from the point of view held by Axel Honneth, in which Foucault and Habermas are understood as rival developments of the problematic fields open by Frankfurt School, Adorno and Horkheimer in particular. We propose that is the conduct in face of the Enlightenment that departs Habermas and Honneth from Foucault and also from Adorno and Horkheimer. We draw up, thus, a rapprochement between Foucault and the first generation of the Frankfurt School, which lean on initially on Honneth's criticism toward one and the other one, then to overcome it, showing, at the same time, the common points - centered in the radical criticism of reason - and the reasons for consider them as responsible for distinct philosophical enterprise.

Keywords: Critical Theory; Frankfurt School; Foucault; Adorno; Horkheimer.

\footnotetext{
^ Endereço para correspondência: Universidade do Estado do Rio de Janeiro, Instituto de Psicologia. Rua São Francisco Xavier, 524/10 andar, sala 10.009, bloco F - Maracanã, Rio de Janeiro, CEP 20550-013.E-mail: leomirhilario@yahoo.com.br, dudalealc@uol.com.br
} 
De acordo com Honneth (2009a[1985], p. 21), em sua obra dedicada ao estudo das fases sucessivas da Teoria Crítica, Foucault e Habermas podem ser entendidos como "desenvolvimentos rivais dentro de um âmbito de questões que foi previamente aberto pela Teoria Crítica". Interessa-nos não tanto a rivalidade entre estes dois desenvolvimentos, mas sobretudo o modo como Foucault se aproxima da primeira geração de teóricos críticos, principalmente Adorno e Horkheimer. Trata-se, deste modo, de investigar um pouco mais este gesto inédito, por parte de Honneth, de vincular Foucault à teoria crítica. ${ }^{1}$ Portanto, a questão mais geral que propomos neste artigo é: o que, com efeito, torna as análises destes autores próximas a ponto de que possamos concebê-las como pertecentes a uma mesma linha de pensamento?

Para Martin Jay (1996), historiador da Escola de Frankfurt, o pensamento francês contemporâneo - Bataille, Lyotard, Derrida, Deleuze e Foucault, dentre outros - possui pontos de convergências com representantes da Teoria Crítica, em especial Adorno e Horkheimer. Jay (1988, p. 22) comenta ainda que estes vínculos vão além de simples aproximações ocasionais, pois é possível discernir, na figura de Walter Benjamin, uma conexão mais histórica. Uma vez que durante seu exílio em Paris, nos anos 1930, o mesmo era conhecido no "círculo de protodesconstrucionistas" do Collège de Sociologie, liderado por Georges Bataille, Pierre Klossowski, Roger Caillois e Michel Leiris.

A Escola de Frankfurt teria encontrado um novo público para as suas obras devido ao retorno de algumas de suas problemáticas operado por estes autores, como no caso específico da crítica da razão:

A crítica radical da tradição ocidental da racionalidade, instrumental e tecnológica, mais extensivamente elaborada na Dialética do Esclarecimento, com suas turvas considerações sobre o entrelaçamento entre mito e a razão, pode ser vista como potencialmente coerente com a desconfiança pós-modernista para com todas as versões da razão (JAY, 1996, p. 16).

No caso particular de Foucault, Jay (1996, p. 17) salienta que a história genealógica do corpo, a hostilidade à normatização e à disciplina, a atenção micrológica aos detalhes e a análise das relações entre conhecimento e poder, têm sido vistos como próximos às problemáticas centrais da primeira geração frankfurtiana, apesar da avaliação crítica da hipótese repressiva marcuseana presente no primeiro volume da História da sexualidade (FOUCAULT, 1998). A propósito, Foucault teria reconhecido pontos em comum entre sua própria análise da sociedade disciplinar da modernidade e o "mundo administrado" de Adorno (JAY, 1988, p. 22).

Também Wiggershaus (2006, p. 36) enxerga uma proximidade quase literal entre as obras de Adorno e Foucault no que se refere a uma crítica racional da razão. Na mesma linha, Habermas (1997, p. 132) afirma que "há, é claro, muitas semelhanças entre a dialética negativa e os procedimentos de desconstrução, de um lado, e a crítica da razão instrumental e a análise da formação de discurso e 
poder, de outro". Dews (1996, p. 51), por sua vez, observa o aumento das reflexões acerca das afinidades temáticas entre o trabalho de pensadores franceses recentes, comumente agrupados sob o rótulo de "pós-estruturalismo", e o pensamento da primeira geração da Escola de Frankfurt.

Ainda na opinião de Jay (1996), comparar Foucault e a Escola de Frankfurt tornou-se frequente. Para defender essa opinião, ele cita dois livros: a coletânea organizada por Kelly (1994), que não é propriamente um trabalho que tem por objeto esta relação, mas sim um conjunto de artigos que versam sobre questões entre Foucault e Habermas; e a tese de doutoramento de Honneth, publicada em 1985, Crítica do Poder, a qual, com efeito, tem por um dos objetos de investigação os pontos de aproximação entre Foucault e a Escola de Frankfurt, inclusive situando o pensamento daquele como desenvolvimento rival da teoria crítica, em contraponto com Habermas.

Em determinado ponto da tese, Honneth (2009a[1985], p. 301) conclui que "nem a teoria crítica de Adorno nem sua continuação sistêmica, a teoria do poder em Foucault, proporcionam-nos instrumental adequado para analisar as forma de integração tardo-capitalistas". Esta conclusão deixa claro que se por um lado Honneth, de modo pioneiro, considera a obra de Foucault um "desenvolvimento" das problemáticas abertas pela primeira geração frankfurtiana, por outro lado toma partido do desenvolvimento rival, isto é, das formulações de Habermas (2012).

O que buscaremos, neste artigo, concordando inicial e parcialmente com essa caracterização dos desenvolvimentos da teoria crítica, é refletir acerca dos pontos que permitem a Honneth efetuar esta opção por Habermas, ${ }^{2}$ para que nos seja possível questionar se não há outra forma de conceber esta proximidade entre Foucault e a primeira geração frankfurtiana, em especial a partir dos pontos salientados por Jay: a crítica da racionalidade moderna articulada com a teoria da sociedade. Ou seja, teceremos uma costura entre Foucault e a primeira geração da Escola de Frankfurt, que se apoia inicialmente na crítica de Honneth tanto a um quanto a outro, para em seguida ultrapassá-la, mostrando, ao mesmo tempo, pontos em comum e as razões para que não se confundam.

Considerando criticamente a avaliação feita por Honneth da análise social de Foucault, separamo-la em três eixos de investigação como formas de encaminhá-las em direção a possíveis respostas: a) o primeiro diz respeito às relações entre razão, poder e sociedade; b) o segundo, concerne às relações entre sujeito, poder e liberdade; c) terceiro, a questão da crítica do "Iluminismo". ${ }^{3}$ Estes encaminhamentos, se pertinentes, podem nos conduzir a outra forma de conceber a proximidade de Foucault com Adorno/Horkheimer, buscando afirmar a atualidade de sua crítica social. Deste modo, sublinhamos que, embora busquemos interrogar a vinculação que Honneth opera entre Foucault e a Escola de Frankfurt, não se trata simplesmente de realizar uma defesa, mas sim de demonstrar como esta proposta de vinculação obnubila o que há de mais produtivo em Foucault, do ponto de vista da "atualização da teoria crítica". 


\section{A vinculação de Foucault com a Escola de Frankfurt}

Para chegar a conclusão de que nem Adorno nem Foucault nos proporcionam instrumental analítico capaz de explicar as formas de integração das sociedades contemporâneas, Honneth (2009a, p. 275) avalia o pensamento de Foucault com base em três argumentos centrais: primeiro, a constatação de que Foucault seria guiado por um "funcionalismo orientado historicamente", que o levaria (segundo ponto) a uma "desvalorização dos progressos da modernidade", já que mudanças significativas no que diz respeito a liberdades individuais, sociais e políticas, são vistas a partir somente do prisma da função que desempenham no processo sistêmico de intensificação do poder, fazendo com que as ações sociais e suas resultantes - transformações da ordem jurídica e criação de instituições sociais - perdessem autonomia diante desse processo de otimização do poder sobre a sociedade; e, por fim (terceiro argumento) ocasionaria uma visão de que a subjetividade se forma a partir das coações externas, isto é, como resultado de condicionamentos constantes, descrevendo-a, assim, de modo behaviorista, ou seja, concebendo os sujeitos como "criaturas informes, totalmente suscetíveis de serem condicionadas” (HONNETH, 2009a, p. 286; 299).

Estes três pontos seguem o fio condutor de uma rejeição da "unilateralidade analítica da Modernidade", ${ }^{4}$ isto é, Honneth discorda frontalmente do que ele supõe ser a visão de Foucault da racionalidade moderna e do papel desempenhado pelo Iluminismo, que consistiria em afirmar a primazia de um processo de intensificação das formas de sujeição no tecido social, cujo elemento central é a conexão interna dos saberes com os poderes instituídos. Desta forma, a sociedade seria tratada como um sistema autorregulado, cujos conflitos entre os atores sociais não passariam de atualizações sistêmicas, sem possibilidade de interrupção ou modificação da lógica do poder. Porém, seria assim mesmo?

A aproximação realizada por Honneth possui dois pontos que nos parecem problemáticos: o primeiro deles é realizar uma abordagem do pensamento foucaultiano que prescinde da filosofia, sobretudo de sua relação com a filosofia moderna, principalmente em direção a Kant e a problemática do Iluminismo, ocorrida com maior ênfase no último período de sua atividade intelectual. As críticas de Honneth estão referidas principalmente ao que se pode chamar de "genealogia do poder" ${ }^{\prime \prime}$ e por isso não focalizam os redimensionamentos provocados por Foucault na questão do sujeito, os quais situam de outra maneira as relações entre poder e coerção, liberdade e história, ação e governo. $\mathrm{O}$ segundo ponto problemático é que a realização dessa proximidade entre Foucault e a Escola de Frankfurt desconsidera a forma como o primeiro entendia sua pertença ao conjunto de questões lançados pela primeira geração de frankfurtianos, sobretudo nos anos que vão de 1978 a 1984 e que permitem estabelecer proximidade no que se refere às relações entre razão, poder e sociedade.

As várias menções de Foucault à Escola de Frankfurt coincidem com o momento no qual ele toma por objeto de suas reflexões a Aufklärung, isto é, o Iluminismo ou Esclarecimento. Seguimos aqui a opinião de Higuera (2011) segundo a qual, em 1978, iniciou-se um ciclo, finalizado em 1984, onde Foucault repetidas 
vezes refletiu acerca do conceito de Iluminismo e, por consequência, da crítica da razão. Os textos mais significativos deste ciclo são: $O$ que é a crítica? (Crítica e Esclarecimento), de 1978, Seminário sobre o texto de Kant: O que é o Esclarecimento?, trata-se aqui da primeira aula do curso de 1983, O Governo de Si e dos Outros, e, por fim, O que são as Luzes?, de 1984 (FOUCAULT, 2008b[1984], 2010a, 2012[1978]). Eribon (1996, p. 175) também sublinha que 1978 foi o ano em que se inaugurou uma longa série de textos nos quais Foucault sublinha a afinidade com a Escola de Frankfurt.

\section{RAZÃO, PODER E SOCIEDADE: A HISTÓRIA COMO FERRAMENTA DE CRÍTICA SOCIAL}

Ao mesmo tempo em que prescinde da filosofia ou da proximidade filosófica de Foucault com o pensamento moderno, em especial da filosofia kantiana, Honneth procura deslocar suas divergências para o terreno da sociologia, usando assim um "léxico sociológico", isto é, um conjunto de conceitos oriundos da sociologia para avaliar o pensamento foucaultiano. Assim, suas críticas estão baseadas num suposto "funcionalismo orientado historicamente" por parte do "modelo teórico-sistêmico" de Foucault.

O funcionalismo, em resumo e de acordo com Boudon (1990, p. 111-112), é uma hipótese inspirada no organicismo do século XIX segundo a qual os elementos da sociedade constituem um todo indissociável, desempenhando papel vital na perpetuação do equilíbrio do conjunto. Neste sentido, o funcionalismo pressupõe a estabilidade e integração dos sistemas sociais, explicando os conflitos, instituições e modificações sociais a partir do esclarecimento das funções sistêmicas que desempenham. Para Levine (1997) e Cuin (1994), o funcionalismo foi o principal legado da tradição sociológica francesa, introduzindo-se por dois caminhos: um pela antropologia social anglo-saxã, cujos porta-vozes foram Radcliffe-Brown e Malinoswki; outro pela apropriação direta da obra de Durkheim realizada por Parsons e Merton. Há, ainda de acordo com Levine e Cuin, um duplo problema analisado pelo funcionalismo: o das condições de manutenção e do funcionamento social, por um lado, e o das modalidades da ação social, por outro. Entram em jogo os imperativos funcionais - adaptação ao meio exterior, realização das metas, integração dos atos e manutenção dos modelos latentes.

Honneth situa sua crítica sobretudo na exposição de Foucault (2009), em Vigiar e punir, segundo a qual foi devido a uma mudança na economia de poder, e não pelo avanço progressista da razão iluminista como promotora da humanização do direito de punir, que os suplícios deram lugar ao devido processo legal e à emergência das instituições disciplinares, como os presídios. Seria claro o funcionalismo foucaultiano neste exemplo, já que a sociedade disciplinar opera para formar sujeitos dóceis e úteis de modo que estes se tornem mais produtivos do ponto de vista do capitalismo, determinante em última instância, ${ }^{6}$ das modificações sociais e políticas. Então é como se fosse o imperativo sistêmico de "valorização do valor" capitalista que comandasse as modificações ocorridas na sociedade. 
Mas o que é próprio das disciplinas é que elas tentam definir em relação as multiplicidades uma tática de poder que responde a três critérios: tornar o exercício do poder o menos custoso possível (economicamente, pela parca despesa que acarreta; politicamente, por sua discrição, sua fraca exteriorização, sua relativa invisibilidade, o pouco de resistência que suscita); fazer com que os efeitos desse poder social sejam levados a seu máximo de intensidade e estendidos tão longe quanto possível, sem fracasso, nem lacuna; ligar enfim esse crescimento "econômico" do poder e o rendimento dos aparelhos no interior dos quais se exerce (sejam os aparelhos pedagógicos, militares, industriais, médicos), em suma fazer crescer ao mesmo tempo a docilidade e a utilidade de todos os elementos do sistema (FOUCAULT, 2009, p. 206).

A partir desta citação, Honneth compreende que a investigação histórica foucaultiana é concebida de modo funcionalista porque compreende a organização social como complexo de estratégias que atendem a imperativos sistêmicos, no caso o da intensificação do poder: os processos sociais atendem à conservação de determinado diagrama de poder político, estando assim submetidos à lógica de "incremento de poder" (HONNETH, 2009a, p. 278).

É indiscutível a pertinência da crítica de Honneth naquilo que se refere à genealogia foucaultiana. Muito embora seja mais do que necessário, diante dessa crítica, relembrar as últimas frases de Vigiar e punir:

E que finalmente o que preside a todos esses mecanismos não é o funcionamento unitário de um aparelho ou de uma instituição, mas a necessidade de um combate e as regras de uma estratégia. [...] Nessa humanidade central e centralizada, efeito e instrumento de complexas relações de poder, corpos e forças submetidos por múltiplos dispositivos de "encarceramento", objetos para discursos que são eles mesmos elementos dessa estratégia, temos que ouvir o ronco surdo da batalha (FOUCAULT, 2009, p. 291).

Se Foucault realmente entendesse os conflitos sociais a partir de sua função sistêmica, não teria claramente separado, de um lado, combates e batalhas e, de outro, as regras de uma estratégia ou os dispositivos. Além disso, não há funcionalismo em Foucault também porque não há centro de emergência do poder. Não há aparelho central ou instância reguladora e funcional que comande estas incessantes formas de luta engendradas pelos atores sociais ou que dê a última palavra a respeito dos conflitos. $\mathrm{O}$ que marca a diferença crucial entre Foucault e o funcionalismo é sua rejeição ao entendimento da sociedade como sistema em busca de estabilidade, equilíbrio e consenso. 
De acordo com Vitullo (2007, p. 65), os funcionalistas, como Parsons e Merton, entendem o conflito como uma patologia que deve ser reprimida e eliminada, pois seria disfuncional à sobrevivência do sistema social. Ora, para Foucault, não há relação social sem luta, embate, estratégia.

Por tudo isso, afirmar que Foucault adere a determinados pressupostos funcionalistas em sua análise nos parece algo questionável.

É bem verdade que a noção de "funcionalismo" em Honneth é bastante singular e se refere, em uma palavra, ao fato de que Foucault também analisaria duas instâncias separadas, nas quais uma delas subjuga a outra sem nenhuma mediação. Apesar disso, fez-se mister, primeiramente, distanciar Foucault daquilo que sociologicamente se entende por "funcionalismo" e, a partir de agora, problematizar se efetivamente há algum resquício funcionalista no pensamento foucaultiano.

Deste modo, devemos responder : se o uso que Foucault faz da história não é funcionalista, o que é? Em outras palavras, se não é a adaptação sistêmica, qual é o estatuto dos acontecimentos no uso crítico da história realizado por Foucault; e qual função de tal uso em seu pensamento, no que se refere às relações entre sociedade, razão e poder?

Podemos encontrar a resposta para essas perguntas num conhecido debate travado entre Foucault e o historiador Jacques Leonard, em torno de Vigiar e punir. ${ }^{7}$ Dentre as críticas de Leonard a Foucault, duas nos servem bastante por causa da resposta que Foucault lhes deu: a primeira, de que o século XIX não é unicamente o palco de uma "normalização massiva", mas de "um conjunto de lutas políticas e sociais articuladas" (LEONARD, 1982, p. 18), o que levaria Foucault a exagerar a racionalização e normalização da sociedade francesa na primeira metade do século XIX, minimizando, em vários terrenos, a resistência aos hábitos do passado e subestimando a importância da desordem e do caos; a segunda é que Foucault descreve uma "maquinaria sem mecânico" (LEONARD, 1982, p. 16) próxima de um universo kafkiano, descrição que impossibilitaria responder questões como: de quem são ou quem promove as estratégias de poder? De quem é esse poder? Se há uma batalha em curso permanente no tecido social, essa batalha é de quem contra quem?

Em resposta a Leonard, Foucault sublinha a diferença entre "analisar um problema e estudar um período". Foucault nega que seu trabalho seja sobre a sociedade francesa em um período determinado, nega também que seja sobre as prisões da França entre 1760 e 1840. Ele diz que se trata de analisar a razão que foi posta em prática na reforma do sistema penal quando se decidiu introduzir a prática do encarceramento (FOUCAULT, 1982, p. 43). É neste sentido que podemos entender o uso da história por Foucault como modalidade de crítica da razão punitiva, uma vez que está em jogo a análise desta 
racionalidade que não é simplesmente princípio de teoria e de técnicas científicas, que não produz simplesmente formas de conhecimento e tipos de pensamento, mas que está ligada por laços complexos e circulares a formas de poder (FOUCAULT, 1982, p. 47).

Foucault responde a Leonard que fala em sociedade disciplinar e não em "sociedade disciplinada", o que, aí sim, daria razão a seu interlocutor na acusação de "normalização massiva" sem oposição. É sobretudo na mesa-redonda de 1978 que Foucault explicita a acontecimentalização (événementialisation) como princípio de inteligibilidade de seu uso da história. Acontecimentalização entendida como, em primeiro lugar, ruptura de evidência, ou seja, demonstração de que aquilo que aconteceu não era tão evidente, inevitável ou desenvolvimento evolutivo natural do anterior. Em segundo lugar, acontecimentalizar consiste em encontrar as conexões, encontros, apoios, bloqueios, relações de força e estratégia, que em determinado momento formam o que logo funcionará como evidência, universalidade e necessidade.

Vê-se que essa leitura da história que enfatiza o acontecimento é diferente da análise funcionalista: enquanto uma tem como procedimento tratar como acaso os encontros que formam um determinado dispositivo, como por exemplo a disciplina, outro toma os acontecimentos históricos como fenômenos de superfície de uma lógica subjacente inevitável e inelutável. Acontecimentalizar é

expor como acontecimento, resultado imprevisto de uma
miríade de processos encontrados, o que correntemente se
percebe como estrutura universal, crença inscrita no coração
humano ou produto de uma necessidade racional, seja sob
a forma do progresso dialético ou de aperfeiçoamento
acumulativo (GARCÍA, 1995, p. 21).

Trata-se, portanto, de analisar a racionalidade enquanto acontecimento, isto é, como multiplicidade de tipos singulares construídos no interior de práticas sociais diversas (racionalidade psiquiátrica, clínica, punitiva, sexológica etc.). É neste sentido que podemos defender que a leitura foucaultiana da história não é funcionalista. Trata-se mais de um recurso filosófico à história na direção de uma crítica da razão que seja indissociável da análise de uma determinada sociedade, daquilo que emerge como problema e articula discursos, saberes, instituições, governos etc. Foucault toma a história como ferramenta de análise que lhe permite diagnosticar o presente através do estudo das condições que o tornam possível e da análise dos jogos de forças que o compõem, relacionando criticamente razão, poder e sociedade em direção ao diagnóstico do presente.

Em uma conferência proferida a 27 de maio de 1978, intitulada $O$ que é a crítica? (Crítica e Aufklärung), Foucault (2012[1978]) esboça de maneira bastante clara o que significa este recurso à história. Após afirmar que o problema entre ratio e poder é o que o irmana com a Escola de Frankfurt, Foucault propõe uma "prática histórico-filosófica", ou seja, uma análise onde a história apareceria 
atravessada pela questão das relações entre as estruturas de racionalidade que articulam o discurso verdadeiro e os mecanismos de sujeição que lhe estão ligados. A primeira característica dessa prática seria "dessubjetivar a questão filosófica pelo recurso ao conteúdo histórico, libertar os conteúdos históricos pela interrogação sobre os efeitos de poder, conteúdos cuja verdade (de que, supostamente, derivam) é afetada por esses efeitos" (FOUCAULT, 2012[1978], p. 66).

A “acontecimentalização", de que falamos anteriormente, refere-se ao procedimento desta "prática" que permite estabelecer conexões entre mecanismos de coerção diversos (conjuntos de legislação, regulamentos, dispositivos etc.) e conteúdos de conhecimento (a noção de saber, que se refere a todos os procedimentos e a todos os efeitos de conhecimento que são aceitáveis num dado momento e num domínio definido). Portanto, o objetivo desta "prática histórico-filosófica" é saber:

quais são os laços, quais são as conexões que podem encontrar-se entre mecanismos de coerção e elementos de conhecimento, que movimentos de reenvio e apoio se criam de uns para os outros, o que é que leva a que um dado elemento de conhecimento possa assumir efeitos de poder, num sistema como esse, a um elemento verdadeiro ou provável ou incerto ou falso, e o que é que leva a que um dado procedimento de coerção adquira a forma e as justificações próprias de um elemento racional, calculado, tecnicamente eficaz, etc. (FOUCAULT, 2012[1978], p. 67).

Assevera Foucault que nesta "prática" não se trata de descrever o que é saber e o que é o poder e como um reprimiria o outro ou como o segundo abusaria do primeiro. A questão está em descrever um nexo de saber-poder que permita identificar o que constitui a aceitabilidade de determinado sistema, seja ele o sistema da doença mental, da penalidade, da delinquência, da sexualidade etc.

Não há, portanto, nem orientação funcionalista em Foucault, nem tampouco pressuposição de duas dimensões (da história e da sociedade, por exemplo) que não encontram pontos de mediação. Ao contrário, as dimensões do poder e do saber se situam exatamente neste ponto intermediário. A inscrição do sujeito neste diagrama não implica passividade. Se há aceitação dos sistemas postos é como resultado de uma miríade de processos que envolvem muito mais do que o convencimento.

\section{SuJeito, PODER E Liberdade: Do ANTAgonismo AO AGONiSMo}

Outro ponto passível de questionamento na análise dos vínculos entre o pensamento foucaultiano e a primeira geração da Escola de Frankfurt, efetuada por Honneth, é a ausência de menções ao modo como o próprio Foucault entende os termos desta aproximação. O período de 1978 a 1984 é muito fecundo a este respeito, pois Foucault reiteradas vezes menciona a teoria crítica, inclusive refletindo acerca de sua inserção no campo problemático aberto pela primeira geração frankfurtiana. É a partir deste período específico que podemos entender como 
Foucault tematizou as relações entre sujeito, poder e liberdade em direção a uma relação de agonismo entre indivíduos e governo, muito além, portanto, de uma perspectiva antagonista, funcionalista ou behaviorista.

No final de 1978, em Paris, Foucault é entrevistado por Duccio Trombadori. Trata-se mais de uma conversa livre sobre o próprio percurso intelectual de Foucault e menos de uma entrevista. Os temas vão da concepção que Foucault tem do próprio trabalho, da recepção de sua obra, da resposta às críticas e aos críticos, dos componentes culturais de sua formação intelectual, enfim, são questões que envolvem o pensamento foucaultiano e seu contexto. Interessam-nos nesta conversa as palavras proferidas por Foucault no que se refere à sua relação com a Escola de Frankfurt.

Trombadori pede a Foucault que fale de como seu pensamento se situa em relação à Escola de Frankfurt, ao que o entrevistado responde:

No que me concerne, penso que os filósofos dessa Escola colocaram problemas em torno dos quais ainda penamos: notadamente, o dos efeitos de poder em relação a uma racionalidade que se definiu histórica e geograficamente no Ocidente, a partir do século XVI. O Ocidente não teria podido chegar aos resultados econômicos, culturais que lhe são próprios, sem o exercício dessa forma particular de racionalidade (FOUCAULT, 2010c, p. 323).

A primeira observação a ser pontuada é a de que existe, de acordo e a partir do próprio Foucault, um solo problemático comum à Escola de Frankfurt e a ele, a correlação entre racionalidade e efeitos de poder. Assim, o problema da Dialética do Esclarecimento, da conversão da racionalidade em dominação, é retomado por Foucault (2010c): "Não poderíamos concluir que a promessa da Aufklärung de alcançar a liberdade pelo exercício da razão voltou-se, ao contrário, para uma dominação da razão mesma, a qual usurpa mais e mais o lugar da liberdade?". O entrelaçamento entre razão e dominação constitui, assim, tanto para Foucault quanto para Adorno e Horkheimer, uma problemática comum. Para eles, a razão é, portanto, indissociável das redes de poder que se proliferam no tecido social em determinado tempo histórico.

Após esta observação, Foucault faz de longe o maior elogio que já proferiu a uma linha de pensamento:

Quando eu reconheço os méritos dos filósofos da Escola de Frankfurt, eu o faço com a má consciência daquele que deveria tê-los lido bem antes e os compreendido mais cedo. Se eu tivesse lido essas obras, não teria necessidade de dizer muitas coisas, teria evitado erros. Talvez, se tivesse conhecido os filósofos dessa Escola, teria sido tão seduzido por eles que não faria outra coisa senão comentá-los (FOUCAULT, 2010c, p. 324). 
Exagero ou não, o fato é que a admiração de Foucault se demonstra intensamente. Uma conclusão apressada se limitaria a defender, a partir dessas últimas duas admissões da evidente conexão entre os pensamentos em jogo, que existe praticamente uma relação de pertença. Como veremos, no entanto, se de um lado existe uma relação explícita entre Foucault e a Escola de Frankfurt, sobretudo no que toca o campo problemático da relação entre razão e efeitos de poder a ela ligados em determinada sociedade, por outro há sempre uma reticência, uma distância.

A própria continuação da entrevista comprova que a relação entre Foucault e a Escola de Frankfurt é paradoxal. Após essa admiração intensamente evocada, Foucault (2010c, p. 325) pontua algumas questões divergentes, como a questão do sujeito, na qual os frankfurtianos pressuporiam algo que já se encontra aprisionado, e a leitura da história, que não levaria em consideração a dimensão do acontecimento e sua implicação para o devir histórico.

É a questão do sujeito e sua relação com o poder e a liberdade, ponto de tensão entre Foucault e a primeira geração da Escola de Frankfurt, que nos permite questionar outro ponto da crítica de Honneth, a saber: a existência de um suposto teor passivo na noção de sujeito em Foucault, próximo do behaviorismo, onde o papel desempenhado pelos sujeitos seria condicionado pelo processo de adaptação ao meio exterior. Em que pese o fato de que no Vigiar e punir o acento da análise seja colocado nos exercícios de poder e de sua relação interna com a produção de saber em direção à produção de subjetividades dóceis e úteis ao capitalismo, a partir de 1978 a relação entre sujeito e poder é entendida como um tipo de "agonismo" recíproco.

Isto significa que a relação entre liberdade e poder não é antagônica mas "agônica": mais de incitação mútua e menos de confrontação entre duas forças heterogêneas. O poder é concebido como "uma ação sobre ações" (FOUCAULT, 2010b, p. 288), ações sobre ações dos outros para governá-las, canalizá-las, dispor numa direção. Como sublinha Ortega (1999, p. 34), a noção de poder, de cunhagem nietzschiana, característica da genealogia, é substituída por uma ideia de poder como governo, orientado para uma teoria da ação. A noção de governo marca essa leitura agônica de Foucault:

O termo "conduta", apesar de equivocado, talvez seja um dos que permitem melhor atingir aquilo que há de específico nas relações de poder. A "conduta" é, ao mesmo tempo, o ato de "conduzir" os outros (segundo mecanismos de coerção mais ou menos estritos) e a maneira de se comportar em um campo mais ou menos aberto de possibilidades. O exercício de poder consiste em "conduzir condutas" e em ordenar a probabilidade. O poder, no fundo, é menos da ordem do afrontamento entre dois adversários, ou do vínculo de um com relação ao outro, do que da ordem do "governo" (FOUCAULT, 2010b, p. 288). 
O governo emerge como elemento que busca estruturar o eventual campo de ação dos outros. O que significa que entre liberdade e poder não há necessariamente apenas confronto, mas a primeira aparece como condição de existência do segundo. De modo que o poder pressupõe a liberdade: "se há relações de poder em todo o campo social, é porque há liberdade por todo lado" (FOUCAULT, 2006, p. 277).

Mais do que um "antagonismo" essencial, seria melhor falar de um "agonismo" de uma relação que é, ao mesmo tempo, de incitação recíproca e de luta; trata-se, portanto, menos de uma oposição de termos que se bloqueiam mutuamente do que de uma provocação permanente (FOUCAULT, 2010c, p. 290).

Estas análises foucaultianas pressupõem um tecido social no qual os indivíduos tenham liberdade de agir para que possam dobrar o poder, daí as "práticas de liberdade", ${ }^{8}$ as quais consistem em desafiar os limites deste governo de ações, pô-los em dúvida, experimentar novas possibilidades que obriguem, por parte das ações de poder, a inventar novas formas de governo, novos cálculos no curso de uma partida infinita (GARCÍA, 1995, p. 40).

Não se trata, assim, de pura relação de resistência antagônica ou mesmo de submissão funcionalista passiva, mas de "relação formativa" que modifica profundamente as formas de subjetivação e o governo das condutas. Aqui Foucault está muito longe de qualquer descrição próxima do behaviorismo, embora as práticas disciplinares corporais tenham contribuído, em sua leitura genealógica, para a produção de subjetividade.

Na visão de Judith Butler, ao referir-se, no primeiro volume da História da sexualidade, às "artes da existência", ou seja, às ações através dos quais os homens não só definem para si um conjunto de regras de conduta, mas também procuram transformar-se no seu ser singular e fazer da vida, obra, Foucault teria entendido que

essas vidas não se conformam simplesmente com preceitos
ou normas morais numa forma em que os si mesmos, que
consideramos formados previamente ou prontos-a-usar, se
encaixem num molde exposto pelo preceito. Pelo contrário,
o si mesmo molda-se em termos da norma, passa a habitá-la
e a incorporá-la, mas a norma não é, neste sentido, externa
ao princípio através do qual o ser é formado (BUTLER,
2012, p. 86, grifo da autora).

Deste modo, a relação entre norma e sujeito não é de externalidade, não se refere, logo, à passividade ou a uma ética baseada no comando e na obediência. Ao contrário, diz respeito a uma prática ética que implica de modo central a formação do si mesmo. O poder não se refere a algo que exerce pressão sobre o sujeito a partir de fora, algo que subordina, coloca debaixo e relega a uma ordem inferior. Em Foucault, o poder é algo que também "forma" o sujeito (BUTLER, 2001, p. 12), ou seja, podemos dizer, aquilo que torna possível o sujeito. 
A subjetivação implica, como salienta Butler (2001) duas dimensões: dos processos e modos de sujeição e também a dos processos de produção do sujeito. Estão em jogo não apenas a subordinação, mas principalmente a instalação de um sujeito, isto é, processos de subjetivação. "O poder é simultaneamente externo ao sujeito e a própria jurisdição do sujeito" (BUTLER, 2001, p. 26). Mesmo em Vigiar e punir, "a sujeição ou assujeitamento não é apenas uma subordinação, mas também um reforço e manutenção, uma instalação do sujeito, uma subjetivação" (BUTLER, 2001, p. 103).

Vemos então como principalmente a partir de 1978, mas também em alguns lampejos anteriores, conceitos como os de governamentalidade, governo, modos de subjetivação, ética etc., vão tematizar as relações entre sujeito, poder e liberdade para lá da suposta asfixia da genealogia foucaultiana. As relações de poder, portanto, ficam muito mais próximas de jogos estratégicos entre liberdades, "jogos estratégicos que fazem com que uns tentem determinar a conduta dos outros, ao que os outros tentam responder não deixando sua conduta ser determinada" (FOUCAULT, 2006, p. 285). Estas relações de poder são como jogos abertos, de várias possibilidades, onde a liberdade de ação é quesito fundamental.

\section{RUMO A UM BECO SEM SAÍDA OU EM DIREÇÃo À CRÍTICA RADICAL?}

Se, por um lado, Foucault (2009, p. 209) afirma: "as Luzes que descobriram as liberdades também inventaram as disciplinas", pois "as disciplinas reais e corporais constituíram o subsolo das liberdades formais e jurídicas", por outro lado, Adorno e Horkheimer (1985, p. 19) afirmam expressamente que "o esclarecimento é totalitário". Isso conduz, segundo críticos frankfurtianos da segunda e terceira geração, como Habermas e Honneth, a um beco sem saída:

Mas, se é assim, também o próprio exercício crítico encontrase em uma aporia: se a razão instrumental é a forma única de racionalidade no capitalismo administrado, bloqueando qualquer possibilidade real de emancipação, em nome de que é possível criticar a racionalidade instrumental? (NOBRE, 2004, p. 52).

Porém, como defende Nobre, tanto Horkheimer quanto Adorno assumem conscientemente esta aporia, defendendo-a enquanto condição de uma crítica cuja possibilidade se tornou precária. Essa situação paradoxal e aporética da crítica é o que permite a Adorno e Horkheimer pensar o presente histórico marcado pelo fascismo, pelo liberalismo americano e pelo stalinismo. Trata-se de uma crítica aporética, pois, afinal de contas, já não pode mais garantir a emancipação. $\mathrm{O}$ que poria em risco, de acordo com Habermas, o próprio projeto crítico, já que este giraria em falso sobre seu próprio fundamento.

Para resgatar a potência de tal crítica - seja em relação a Foucault ou à primeira geração da Escola de Frankfurt - faz-se necessário retirar a aporia do registro daquilo que obstaculiza ou mesmo impossibilita a crítica e colocá-la na posição segundo a qual a própria crítica é tornada possível: tanto Adorno e 
Horkheimer quanto Foucault, reposicionam a aporia como condição de possibilidade para o exercício do que se pode chamar de "crítica radical" e é desse modo que estes autores convergem na radicalidade da análise do Iluminismo.

Radical aqui no sentido marxiano de quem vai à raiz do problema, neste caso, a relação genética entre racionalidade abstratamente emancipatória e dominação imanentemente eficaz. Tal "crítica radical" defende que no próprio interior da racionalidade moderna existem os elementos de sua dissolução e conversão em dominação, não havendo relação de contaminação ou constrangimento entre razão e dominação, e sim uma relação genética entre razão, sociedade e poder, a qual, ainda, não seria patológica, mas "patogenética". As consequências desse tipo de leitura radical não são de pouca importância, pois enquanto se poderia pensar que a relação entre Iluminismo e barbárie é uma questão de desvirtuação, de traição, ou ainda de constrangimento externo, esta leitura afirma que se trata de consequência lógica, quer dizer, há algo como um "germe totalitário" no seio do projeto emancipatório moderno.

Devido a diferenças existentes na análise da racionalidade entre Foucault, Adorno e Horkheimer, a crítica radical do Iluminismo através da afirmação da indissociabilidade entre razão, sociedade e poder, pode nos servir para vincular estes autores e também para demonstrar como a questão da análise negativa feita por Honneth é concernente à sua divergência com relação ao tipo de crítica - seus objetivos, suas ferramentas, seu procedimento etc. - desenvolvido por Foucault. A suspeita radical que Foucault compartilha com Adorno e Horkheimer diz respeito à cumplicidade entre racionalidade e formas de dominação, o que deixa pouco espaço para a valorização dos potenciais emancipatórios da modernidade.

Assim, analisar as críticas de Honneth significa, também, propor outra forma de se conceber a proximidade do pensamento foucaultiano aos problemas frankfurtianos, em especial ao que McCarthy (1994, p. 243) chamou de “crítica da razão impura". É em torno do problema da crítica da razão e da sociedade, ou seja, dos efeitos de poder ligados a determinadas racionalidades efetivas e do exercício de análise e/ou diagnóstico, que podemos elaborar o entendimento de como se aproximam estes autores de outra maneira, sobretudo através da crítica radical ao Iluminismo.

O pensamento de Foucault, apresentado enquanto desenvolvimento rival ao de Habermas, pode ser encarado como um conjunto de ferramentas de análise que passa ao largo da mudança de paradigma até uma racionalidade comunicativa e busca focalizar outros problemas como o da produção de heteronomia vinculada a discursos e práticas, surgindo então como manutenção da radicalidade na crítica no fim do século XX. Deste modo, em vez de se preocupar com os fundamentos normativos de sua própria crítica, busca problematizar a confiança na Razão, provocando uma desconfiança permanente. Uma crítica que também busca refletir acerca de nosso presente. Se há desenvolvimentos rivais que passam pela teoria crítica, como defendeu Honneth, vale ter em mente a própria visão que Foucault (2010a, p. 22) tinha disso: 
E me parece que a opção filosófica com a qual nos vemos confrontados atualmente é a seguinte. É preciso optar ou por uma filosofia crítica que se apresentará como uma filosofia analítica da verdade em geral, ou por um pensamento crítico que tomará a forma de uma ontologia de nós mesmos, de uma ontologia da atualidade. E é essa forma de filosofia que, de Hegel à Escola de Frankfurt, passando por Nietzsche, Max Weber, etc., fundou uma forma de reflexão à que, é claro, eu me vinculo na medida em que posso.

É assim que podemos defender uma via positiva de vinculação de Foucault com a Escola de Frankfurt, a saber, como "paralelas convergentes", linhas que não se fundem devido a suas singularidades mas também não se afastam em demasia ou a ponto de se antagonizar por causa de seus procedimentos em comum, em especial o objetivo de realizar uma "crítica da razão impura". Sem se tocar por estarem em paralelo na questão dos conceitos de sujeito e racionalidade, porém também sem se afastar por serem convergentes em direção à crítica radical da razão, estes autores podem ser vinculados no que diz respeito às problemáticas em comum e ao campo de tensão recíproco entre suas formulações.

\section{Herança e Crítica do Iluminismo}

A partir das palavras do próprio Foucault compreendemos de que maneira a história é utilizada enquanto modo de crítica social que busca diagnosticar as relações entre razão e os efeitos de poder a ela ligados em determinada sociedade. Assim, sua proximidade com a Escola de Frankfurt pode ser lida como convergência no que se refere às relações entre razão, poder e sociedade. Por outro lado, Foucault redimensiona as relações entre sujeito, poder e liberdade de maneira bastante distante de qualquer condicionamento externo passivo e automático, como argumenta Honneth (2009a, p. 285), ao afirmar que Foucault supõe que são "procedimentos coativos externos que produzem sujeitos", no sentido de que são pressões exercidas através de determinados procedimentos, como a confissão, que produzem sujeitos.

Nesta questão do sujeito Foucault se distancia da Escola de Frankfurt por tematizar de outro modo os vínculos entre sujeito, poder e liberdade, em direção à problematização ética. Apesar das diferenças, propomos que se pode encarar a relação entre Foucault e a Escola de Frankfurt como paralelas convergentes em direção a uma crítica radical e racional da racionalidade moderna, incluído o chamado Iluminismo.

Com relação a este tema da crítica do Iluminismo ou crítica da modernidade, Habermas tece numa entrevista um comentário sobre como Foucault explorou o processo de racionalização a partir de Weber e de como tal leitura pode ser perigosa e conduzir ao irracionalismo:

É necessário mostrar que a "racionalização" de Weber, que foi explorada por Foucault de uma maneira muito diferente no campo da cultura, das relações sexuais, da criminalidade e da insanidade -, é perigosa por ser parcial. Isso porque 
se caracteriza por sua universalização de uma única forma fundamental de racionalidade - razão instrumental, econômica e administrativa. Mas devemos tomar o cuidado para não rejeitar tudo, perdendo os aspectos positivos, e fugir para um novo irracionalismo. É evidente que Foucault corre esse perigo (HABERMAS, 1997, p. 121).

Em 1983, em entrevista a Gérard Raulet, intitulada Estruturalismo e Pós-estruturalismo, provavelmente tendo em vista estas palavras de Habermas, Foucault menciona o que entende por "chantagem iluminista":

Creio que a chantagem que muito frequentemente se exerceu em relação a qualquer crítica da razão, ou a qualquer interrogação crítica sobre a história da racionalidade (ou você aceita a razão, ou cai no irracionalismo) faz crer que não seria possível fazer uma crítica racional da racionalidade. Ora, creio que, desde Max Weber, na Escola de Frankfurt e, em todo caso, em muitos historiadores da ciência como Canguilhem, trata-se de destacar a forma de racionalidade que é apresentada como dominante e à qual se dá o status da razão para fazê-la aparecer como uma das formas possíveis do trabalho sobre a racionalidade (FOUCAULT, 2008a, p. 316).

Quando Foucault fala em "chantagem iluminista" tem em mente justamente essa matriz de pensamento que opera algo que podemos chamar de "Cisão da Razão", isto é, pressupõe que há duas modalidades de razão: uma instrumental, dominadora, intencionada para fins; outra comunicativa, emancipatória, que busca o mútuo entendimento. O conceito de Razão é assim dissociado de seus efeitos de poder.

A chantagem iluminista consiste numa acusação de irracionalismo cujo alicerce é este modelo duplo de racionalidade. Ora, o que ocorre é que tanto Foucault quanto Adorno e Horkheimer não balizam suas análises por uma "Cisão da Razão", mas por uma leitura que entende a razão como inseparável de seus efeitos de poder em determinado tecido social, de modo que ela contém em si mesma, na abstração de suas proposições, as condições de possibilidade para as práticas de poder. "Uma análise social desta natureza é indissociável de uma crítica da Razão". Este é um dos principais pontos de aproximação entre estes autores: a afirmação de uma relação interdependente entre razão, poder e sociedade.

Sublinhar o perigo contido na racionalidade não significa recusá-la. Bem como fazer a crítica da razão não é apostar no irracionalismo: consiste em especificar suas materializações no tecido social, seus limites, suas ameaças, suas engrenagens. Esta convergência na análise radical da razão inscreve estes autores num campo de tensão recíproca, uma vez que a razão, para os frankfurtianos, é instrumental: acomete a totalidade e atende aos objetivos do capital; já para Foucault, a racionalidade é estratégica: é fruto e frutifica lutas, enseja embates, relações de poder-saber, modos de subjetivação, não tem fundamento específico e fixo: 
Devemos investigar esse tipo de racionalismo que parece específico da cultura moderna e que se origina na Aufklärung? Acredito que essa tenha sido a abordagem de alguns membros da Escola de Frankfurt. Meu objetivo não é iniciar uma discussão de seus trabalhos. Apesar de serem, na maior parte, importantes e valiosos. Ao contrário, eu sugeriria uma outra forma de investigação das relações entre racionalização e o poder (FOUCAULT, 2010b, p. 276).

Em Foucault, o processo de racionalização é deslocado para racionalidades específicas, como processo que se dá em vários campos: loucura, doença, morte, crime, sexualidade, sujeito etc. Com efeito, isso mantém a tensão entre Foucault e a Escola de Frankfurt, pois, também para aquele "não tem sentido referir-se à razão como uma entidade contrária à não razão" (FOUCAULT, 2010b, p. 273). Maia (2002, p. 71) defende que tanto a crítica foucaultiana da modernidade quanto o diagnóstico formulado pela Dialética do Esclarecimento baseiam-se no reconhecimento de um formidável crescimento dos mecanismos utilizados para o controle a submissão dos sujeitos. As disciplinas e o biopoder se situam na mesma linha de preocupações daquela destacada pela primeira geração da Escola de Frankfurt com a expressa "sociedade administrada". Como se pode ver, a relação entre estes pensadores é bastante complexa, ora de convergência analítica, ora de dissonância de procedimento.

Se, por um lado, as noções de racionalidade instrumental e estratégica, afastam os autores e compõem suas formas singulares de análise, a noção de que a racionalidade seja inseparável de seus efeitos de poder é comum a ambas. A proposição de uma paralela convergência não sinaliza, portanto, a mera confluência pacífica entre o pensamento de Foucault e a Escola de Frankfurt, mas a tensão constante entre dois projetos de análise que possuem diferenças e singularidades. Ou seja, tanto Foucault quanto Adorno e Horkheimer, ainda que seus procedimentos de análise e campos de ação sejam diferentes, mobilizam-se por um problema fundamental, a saber, os efeitos de poder ligados ao exercício de uma racionalidade efetiva numa dada sociedade (ERIBON, 1996, p. 175).

Nesta leitura a razão produz a sociedade e vice-versa. Não se trata de afirmar que seja a razão, no sentido de um conceito específico de racionalidade, que fundamenta e viabiliza a crítica social, mas de afirmar a indissociabilidade entre análise social e crítica da razão. Pode-se dizer que, em Habermas e Honneth, elas estão devidamente separadas, pois se considera que um conceito específico de racionalidade, comunicativa, por exemplo, é condição de possibilidade para uma crítica da sociedade. Crítica esta que, se prescindir dessa operação de cisão no interior da racionalidade, fica emaranhada na aporia fundamental de ter de apelar à razão que ela mesma critica radicalmente.

Esta aporia pode ser exemplificada através da conduta - para alguns, como Habermas, favorável ou contrária - diante do que se chama Iluminismo. Propomos, contudo, ler estas opções de outra forma: aqueles que entendem o Iluminis- 
mo como promotor de avanços e progressos na ordem da moral, da sociedade, da cultura etc., e aqueles para os quais se trata de um movimento em si mesmo contraditório, produtor, ao mesmo tempo, de autonomia e heteronomia.

Para Foucault, o Iluminismo é parte integrante de modos de dominação exercidos no terreno da subjetividade, sexualidade e criminalidade. Para Adorno e Horkheimer, o ponto de chegada do Iluminismo foi exatamente aquilo que se poderia considerar como seu reverso, isto é, regimes totalitários e uma sociedade da qual o horizonte utópico está ausente. Como aponta Assoun (1991, p. 85) a respeito desta tese, é como se a repressão estivesse na Razão como o verme no fruto. $\mathrm{Ou}$, ainda para usar outra imagem a este respeito: para Adorno e Horkheimer, razão e dominação são siameses que nem o mais hábil cirurgião, munido com o mais fino bisturi da racionalidade comunicativa, pode separar uma da outra (MAESTRE, 1988, p. XX).

Para Foucault e a Escola de Frankfurt, ao menos no que se refere à chamada primeira geração, as relações entre razão, sociedade e poder são de interdependência, de modo que no tecido social existem racionalidades efetivas que são analisadas e diagnosticadas pela análise crítica. Não há, portanto, como realizar uma crítica independente do modo efetivo de racionalidade, nem tampouco se pode prescindir da análise de uma determinada sociedade.

Desta maneira, o que vincula Foucault à Escola de Frankfurt são menos eventuais limitações em comum de suas análises e mais a atividade diagnóstica de uma reflexão que busca simultaneamente equipar-se da história, da filosofia e da teoria social em direção a uma crítica radical. Neste sentido, são "duas formas de crítica da razão impura", como defende McCarthy (1990, p. 53), já que não enxergam uma racionalidade pura ou a priori, mas contaminada pela experiência histórica, social e política. Estes autores procuraram diagnosticar o que pode se chamar de sociedade disciplinar, administrada ou unidimensional, ${ }^{9}$ na qual o controle político dos indivíduos se conecta diretamente aos modos de sujeição e à produção de saber. Esquematicamente, podemos dizer que estes autores se aproximam quando tematizam as relações entre razão, poder e sociedade, porém se distanciam quando o que está em jogo são as ligações entre sujeito, poder e liberdade.

Para Jameson (1997, p. 324), o pensamento de Adorno permanece até final do século XX mais atual do que nunca. Esse julgamento pode ser contextualizado pela derrocada do Estado de Bem-Estar Social e pela impossibilidade de encarar a regulação estatal dos conflitos sociais de maneira positiva. Parece, então, que "entrou água" no discurso que valoriza potenciais positivos da modernidade, sobretudo na atual sociedade em que se acumulam constantemente riscos das mais variadas formas: ecológicos, financeiros, militares, terroristas, bioquímicos etc. (BECK, 2010). Neste sentido, a crítica radical permanece numa situação paradoxal: pois é concomitantemente "aporética" e "urgente".

Quase 30 anos depois da afirmação de Honneth, é preciso problematizar se realmente o ponto de vista radical de Adorno, Horkheimer e Foucault, com relação os avanços da modernidade, são inatuais. Isto é: se oferecem um instru- 
mental inapropriado para refletir acerca das formas de integração das sociedades contemporâneas, principalmente em nossa sociedade brasileira bastante distante de regular seus conflitos sociais de maneira satisfatória pela via estatal.

\section{Notas}

${ }^{1}$ Neste sentido, o presente artigo desenvolve e aprofunda alguns argumentos lançados inicialmente em "Michel Foucault e a Escola de Frankfurt: reflexões a partir da obra Crítica do Poder", de Axel Honneth" (HILÁRIO; CUNHA, 2012a).

${ }^{2}$ Ao afirmar isso, não queremos dizer que a elaboração teórica de Honneth é mero apêndice ou continuação das formulações habermasianas. Isto seria um erro na medida em que seu ponto de partida é efetivamente uma relação entre Foucault e Habermas em direção a uma teoria social que contenha, ao mesmo tempo, o elemento da luta e do consenso normativo. Logo, queremos tão somente salientar para o fato de que há duas concepções de modernidade distinta entre estes dois autores e Honneth adere indubitavelmente à habermasiana, isto é, aquela constituída por uma dialética entre racionalidade comunicativa e instrumental.

${ }^{3}$ Aufklärung, em alemão. Usualmente traduzido por Iluminismo, Esclarecimento ou simplesmente Luzes, e se configura, de acordo com Reale e Antiseri (1990), não tanto como um compacto sistema de doutrinas, mas muito mais como movimento em cuja base está a confiança na razão humana, cujo desenvolvimento é a condição de progresso para a humanidade e de libertação dos vínculos cegos e absurdos da tradição, das raízes da ignorância, da superstição, do mito e da opressão. Embora a questão do Iluminismo não se inicie nem termine com Kant (2005), a sua proposta de que "o Esclarecimento é a saída do homem do seu estado de menoridade", processo que consiste na utilização da razão para que o homem possa se constituir como livre e dotado de uma vontade racional autônoma, constitui referência maior quando se fala da Aufklärung.

${ }^{4}$ Esta expressão é usada por Duarte (1997c, p. 60) como aquela que supostamente representaria a visão de Adorno da modernidade do ponto de vista de Habermas. Criticando esta apropriação, Duarte (1997b, p. 136) sustenta que inexiste em qualquer obra de Adorno a declaração de que não haja saída do Esclarecimento, havendo pontos positivos desta análise da modernidade, sobretudo no que tange à negatividade, responsável por introduzir um elemento reflexivo na racionalidade moderna. Neste ponto de avaliação do pensamento de Adorno frente a razão e ao Iluminismo, como em outros, Habermas e Honneth convergem literalmente. Embora renomadamente representantes da segunda e terceira geração da Escola de Frankfurt, pode-se sustentar, como Duarte (1997a, p. 180) o faz, que o pensamento de Adorno está em claro desacordo com o de Habermas. Caberia, então, a pergunta: não estaria Foucault, devido à sua análise crítica do Iluminismo, muito mais próximo de Adorno?

${ }^{5}$ Segundo Machado (2006, p. 167), a palavra genealogia foi introduzida em Vigiar e punir, denotando uma análise histórica das condições políticas de possibilidade dos discursos. Com o procedimento genealógico, Foucault põe novas problemáticas em questão, tais quais a noção de poder molecular, isto é, uma microfísica do poder; a contestação da afirmação de que o poder é puramente negativo e impõe limites, castigos, coerções, ou seja, uma das teses genealógicas é a de que o poder produz subjetividades, assim não destrói o indivíduo, mas o fabrica; a tese da indissociabilidade entre poder e saber, dentre outras problemáticas próprias da genealogia. Para Ewald (1993, p. 20), a genealogia é também uma questão de método, pois ela não coloca os mesmos problemas nem perspectivas da arqueologia do saber que marcou os livros anteriores de Foucault. A genealogia analisa, em resumo, "especificamente o problema do poder e do corpo (dos corpos), coloca os problemas a partir da tomada de poder sobre os corpos".

${ }^{6}$ A crítica de Honneth a Foucault é também atravessada por uma crítica ao marxismo. Em outro texto, ele argumenta que a primeira geração frankfurtiana está ligada à tendência, já predominante em Marx, de restringir instrumentalmente a história humana para um desdobramento desenvolvimentista do procedimento societal da natureza (HONNETH, 1999, p. 517). Especificamente no contexto de Vigiar e punir, a argumentação é a de que as disciplinas estão a serviço do imperativo do capital, já que seu objetivo é produzir corpos dóceis e úteis. Portanto, o princípio de inteligibilidade dos acontecimentos históricos no pensamento foucaultiano seria funcionalista da mesma forma que em Marx, na medida em que este supostamente entenderia as modificações ocorridas no tecido social apenas como fenômenos de superfície da modificação das forças produtivas, constituintes da infraestrutura social que determinaria a superestrutura (relações jurídicas, formas de governo, 
discursos, saberes etc.). Novamente, assim como no funcionalismo, este modo marxiano de entender a sociedade levaria a primeira geração da Escola de Frankfurt e também Foucault a não ter a devida consideração pelos atores sociais e aquilo que estes produzem, principalmente contra e de forma autônoma ao sistema vigente.

${ }^{7}$ Trata-se de L'impossible prison (recherches sur Le système penitentiare au XIX siècle par Michelle Perrot - Débat avec Michel Foucault), L'Univers historique, Editions Du Seuil, Paris, 1980. Aqui utilizamos a versão espanhola - La imposible prisión: debate com Michel Foucault (LEONARD, 1982).

${ }^{8}$ Analisamos esta noção de "práticas de liberdade", a partir de Marcuse e Foucault, tomando como objeto de análise a apropriação médica das perversões sexuais, no artigo "Possibilidades éticoestéticas da perversão: a sexualidade perverso-polimorfa como prática de liberdade em Marcuse" (HILÁRIO; CUNHA, 2012b).

${ }^{9}$ Cada uma das denominações possui sua singularidade conceitual que a difere das demais, não permitindo qualquer espécie de substituição como se fossem sinônimos. No entanto, são modos de analisar e diagnosticar o presente que se aproximam na medida em que põem o acento da análise nos processos de dominação e de suas implicações para os modos de vida e de organização social. Neste sentido, pomos lado a lado tais denominações sob a justificativa de que todas convergem naquilo que se refere à leitura crítica radical do presente.

\section{REFERENCIAS}

ASSOUN, P-L. A escola de Frankfurt. São Paulo: Ática, 1991.

ADORNO, T.; HORKHEIMER, M. A Dialética do Esclarecimento: fragmentos filosóficos. Rio de Janeiro: J. Zahar, 1985.

BECK, U. Sociedade de risco: rumo a uma outra modernidade. São Paulo: Ed. 34, 2010.

BOUDON, R. Dicionário de Sociologia. Lisboa: Dom Quixote, 1990.

BUTLER, J. Mecanismos psíquicos del poder. Madrid: Cátedra, 2001.

BUTLER, J. O que é a crítica? Um ensaio sobre a virtude de Foucault. Imprópria: política e pensamento crítico, Lisboa, n. 1, p. 81-98, $1^{\circ}$ sem. 2012.

DEWS, P. Adorno, pós-estruturalismo e a crítica da identidade. In: ZIZEK, S. (Org.). Um mapa da ideologia. Rio de Janeiro: Contraponto, 1996. p. 51-70.

DUARTE, R. Expressão como fundamentação. In: . Adornos: nove ensaios sobre o filósofo frankfurtiano. Belo Horizonte: UFMG, 1997a. p. 161184.

DUARTE, R. Notas sobre a "carência de fundamentação" na filosofia de Theodor W. Adorno. In: Adornos: nove ensaios sobre o filósofo frankfurtiano. Belo Horizonte: UFMG, 1997b. p. 131-144. 
DUARTE, R. Notas sobre modernidade e sujeito na Dialética do Esclarecimento. In: Adornos: nove ensaios sobre o filósofo frankfurtiano. Belo Horizonte: UFMG, 1997c. p. 45-64.

CUIN, C-H. História da Sociologia. São Paulo: Ensaio, 1994.

ERIBON, D. A impaciência da liberdade (Foucault e Habermas). In: Michel Foucault e seus contemporâneos. Rio de Janeiro: J. Zahar, 1996. p. 169181.

EWALD, F. Foucault, a norma e o direito. Lisboa: Vega, 1993.

FOUCAULT, M. El polvo y la nube. In: LEONARD, J. La imposible prisión: debate con Michel Foucault. Barcelona: Anagrama, 1982. p. 37-53.

FOUCAULT, M. História da Sexualidade: o uso dos prazeres. Rio de Janeiro: Graal, 1998. v. 2.

FOUCAULT, M. A ética do cuidado de si como prática da liberdade. In: MOTTA, M. B. da. (Org.). Ética, sexualidade, politica. Rio de Janeiro: Forense Universitária, 2006. p. 264-287.

FOUCAULT, M. Estruturalismo e Pós-estruturalismo. In: MOTTA, M. B. da. (Org.). Arqueologia das ciências e história dos sistemas de pensamento. Rio de Janeiro: Forense Universitaria, 2008a. p. 307-334.

FOUCAULT, M. O que são as Luzes? (1984). In: MOTTA, M. B. da. (Org.). Arqueologia das ciências e história dos sistemas de pensamento. Rio de Janeiro: Forense Universitária, 2008b. p. 335-351.

FOUCAULT, M. Vigiar e punir: nascimento da prisão. Rio de Janeiro: Vozes, 2009.

FOUCAULT, M. O governo de si e dos outros: curso no Collège de France (19821983). São Paulo: Martins Fontes, 2010a.

FOUCAULT, M. O sujeito e o poder. In: RABINOW, P.; DREYFUS, H. (Org.). Michel Foucault, uma trajetória filosófica: para além do estruturalismo e da hermenêutica. Rio de Janeiro: Forense Universitária, 2010b. p. 273-295.

FOUCAULT, M. Conversa com Michel Foucault. In: MOTTA, M. B. da. Repensar a Política. Rio de Janeiro: Forense Universitaria, 2010c. p. 289-347.

FOUCAULT, M. O que é a crítica? (Crítica e Aufklärung) (1978). Imprópria: política e pensamento crítico, Lisboa, n. 1, p. 57-80, $1^{\circ}$ sem. 2012. 
GARCÍA, F. V. Foucault: la historia como crítica de la razón. Barcelona: Montesinos, 1995.

HABERMAS, J. O conservadorismo e a crise capitalista. In: SADER, E. (Org.). Vozes do século: entrevistas da New Left Review. Rio de Janeiro: Paz e Terra, 1997. p. 111-123.

HABERMAS, J. Teoria do Agir Comunicativo. São Paulo: Martins Fontes, 2012.

HIGUERA, J. de. Estudio preliminar. In: FOUCAULT, M. Sobre la Ilustración. Madrid: Tecnos, 2011. p. IX-LXVII.

HILÁRIO, L. C.; CUNHA, E. L. Michel Foucault e a Escola de Frankfurt: reflexões a partir da obra crítica do poder, de Axel Honneth. Trans/Form/Ação, Marília, v. 35, n. 3, p. 157-188, dec. 2012a.

HILÁRIO, L. C.; CUNHA, E. L. Possibilidades éticos-estéticas da perversão: a sexualidade perverso-polimorfa como prática de liberdade em Marcuse. Psicol. USP, São Paulo, v. 23, n. 2, p. 303-326, jun. 2012b. Disponível em: <http://www. scielo.br/scielo.php?script=sci_arttext\&pid=S0103-65642012000200004\&lng= en\&nrm=iso >. Acesso em: 20 dez. 2012.

HONNETH, A. Teoria Crítica. In: GIDDENS, A.; TURNER, J. H. (Org.). Teoria social hoje. São Paulo: UNESP, 1999. p. 503-552.

HONNETH, A. Crítica del poder: fases en la reflexión de una Teoria Crítica de la sociedad (1985). Madrid: Machado, 2009a.

HONNETH, A. Una fisonomía de la forma de vida capitalista. Bosquejo de la teoría social de Adorno. In: Patologías de la razón: historia y actualidad de la teoría crítica. Madrid: $\overline{\text { Katz, } 2009 b . ~ p . ~ 65-84 . ~}$

HONNETH, A. Una patología social de la razón. Sobre el legado intelectual de la Teoría Crítica. In: . Patologías de la razón: historia y actualidad de la teoría crítica. Madrid: Katz, 2009c. p. 27-51.

JAMESON, F. O Marxismo Tardio: Adorno, ou a persistência da dialética. São Paulo: Unesp, 1997.

JAY, M. As idéias de Adorno. São Paulo: Cultrix, 1988.

JAY, M. A imaginação dialética 25 anos depois. In Contemporaneidade e educação: revista semestral de Ciências Sociais e Educação. Rio de Janeiro: IEC, Ano I, n 0, p. 8-21, set. 1996. 
KANT, I. Resposta à pergunta: Que é "Esclarecimento"? (Aufklärung) In: Immanuel Kant: textos seletos. Petrópolis, RJ: Vozes, 2005. p. 100-118.

KELLY, M. (Org.). Critique and power: recasting the Foucault/Habermas debate. Cambridge, MA: MIT, 1994.

LEONARD, J. El historiador y el filosofo. A propósito de: Vigilar y castigar; nascimento de la prisión. In: . La imposible prisión: debate con Michel Foucault. Barcelona: Anagrama, 1982. p. 5-36.

LEVINE, D. N. Visões da tradição sociológica. Rio de Janeiro: J. Zahar, 1997.

MACHADO, R. Foucault, a ciência e o saber. Rio de Janeiro: J. Zahar, 2006.

MAESTRE, A. (Comp.). Estudio preliminar: notas para uma nueva lectura de la Ilustración. In: . ¿Que és ilustración? Madrid: Tecnos, 1988. p. XI-XLIX.

MAIA, A. C. Foucault e Adorno: mapeando um campo de convergências. In: RAGO, M. et al. (Org.). Imagens de Foucault: ressonâncias nietzschianas. Rio de Janeiro: DP\&A, 2002. p. 63-84.

MCCARTHY, T. Filosofía y teoría crítica en Estados Unidos. Foucault y la Escuela de Francfort. Isegoria, n. 1, p. 49-84, maio 1990.

MCCARTHY, T. The Critique of Impure Reason: Foucault and The Frankfurt School. In: KELLY, M. (Org.). Critique and power: recasting the Foucault/ Habermas debate. Cambridge, MA: MIT, 1994. p. 243-282.

NOBRE, M. A Teoria Crítica. Rio de Janeiro: J. Zahar, 2004.

ORTEGA, F. Amizade e estética da existência em Foucault. Rio de Janeiro: Graal, 1999.

VITULLO, G. O lugar do conflito na teoria democrática contemporânea. Tomo, São Cristóvão - SE, n. 10, p. 61-83, jan./jun. 2007.

REALE, G.; ANTISERI, D. História da filosofia: do humanismo a Kant. São Paulo: Paulus, 1990.

WIGGERSHAUS, R. A Escola de Frankfurt: história, desenvolvimento teórico, significação política. Rio de Janeiro: DIFEL, 2006.

Recebido em: 04 de dezembro de 2012

Aceito em: 22 de outubro de 2014 